\title{
Analysis of Continuing Airworthiness Occurrences under the Prism of a Learning Framework
}

\author{
James Clare ${ }^{1}$ and Kyriakos I. Kourousis $1,2, *$ (D) \\ 1 School of Engineering, University of Limerick, V94 T9PX Limerick, Ireland; james.clare@ul.ie \\ 2 School of Engineering, RMIT University, Melbourne, VIC 3001, Australia \\ * Correspondence: kyriakos.kourousis@ul.ie
}

Citation: Clare, J.; Kourousis, K.I. Analysis of Continuing Airworthiness Occurrences under the Prism of a Learning Framework. Aerospace 2021, 8, 41. https://doi.org/10.3390/ aerospace 8020041

Academic Editor:

Alexei Sharpanskykh

Received: 15 December 2020

Accepted: 2 February 2021

Published: 5 February 2021

Publisher's Note: MDPI stays neutral with regard to jurisdictional claims in published maps and institutional affiliations.

Copyright: (C) 2021 by the authors. Licensee MDPI, Basel, Switzerland. This article is an open access article distributed under the terms and conditions of the Creative Commons Attribution (CC BY) license (https:/ / creativecommons.org/licenses/by/ $4.0 /)$.

\begin{abstract}
In this research paper fifteen mandatory occurrence reports are analysed. The purpose of this is to highlight the learning potential incidents such as these may possess for organisations involved in aircraft maintenance and continuing airworthiness management activities. The outputs from the mandatory occurrence reports are aligned in tabular form for ease of inclusion in human factors' continuation training material. A new incident learning archetype is also introduced, which intends to represent how reported incidents can be managed and translated into lessons in support of preventing event recurrence. This 'learning product' centric model visually articulates activities such as capturing the reported information, establishing causation and the iterative nature of developing a learning product.
\end{abstract}

Keywords: aircraft maintenance; airworthiness; learning from incidents; aviation safety; learning taxonomy

\section{Introduction}

Structured and continuous safety management actions, such as collection of data, analysis and intervention can be enabled with the support of the necessary safety intelligence. High quality maintenance and management tasks are some of the essential inputs for safe operations. Continuous information 'harvested' from incident reporting arising from these tasks, is another major part of learning and preserving acceptable levels of safety [1]. Thankfully, serious incidents are becoming less frequent [2] but often because of environmental, cognitive and human centric demands, reportable and unreportable events do occur. The main underpinning aviation regulation in Europe, European Union (EU) regulation 2018/1139 [3] refers to 'management system' and mandates an operator to implement and maintain a management system to ensure compliance with these essential requirements for safe operations; it also aims for continuous improvement of the safety system through learning from incidents.

In the area of continuing airworthiness, the fundamentals of management systems are also extended to incident and occurrence reporting through the implementing conduit of EU regulation 1321/2014 [4]. It is common for incidents to be discovered within organisations and reported with the assistance of such 'systems of systems' [5]. On an operational level, initial human factors training, and company procedures are intended to specify and re-affirm the class and type of occurrence and incident that should be reported. Recent developments in Europe in the guise of EU regulation 376/2014 [6] empower voluntary and confidential reporting and are independent of all other individual obligations. The paper recounts an analysis of 15 occurrences drawn from a repository of reportable incidents. Each incident was assessed, and the report data interpreted to support potential primary and secondary causation factors. To translate these learning points into tangible lessons, causation factors are harmonised with a taxonomy for learning. This taxonomy is based upon the Transport Canada 'Dirty Dozen' [7] human factors terms which feature common aviation human error preconditions. Additionally, a framework is presented in the paper to demonstrate how learning from incidents can be leveraged with best effect in the industry 
segment. Mandatory reportable incidents are notified through the formal mechanism of reporting. Once the incident enters its lifecycle, it ideally transverses a process that transforms the information gathered into knowledge. This knowledge is intended to assist with the prevention of similar future events.

\section{Safety Reporting Background}

\subsection{International and European Regulatory Context}

Safety information databases containing appropriate details of events with potential and latent ancillary contributors are available and can be considered with the assistance of continuous analysis. In the United States a combined effort by the aviation industry, organisations and individuals, known as the Aviation Safety Reporting System (ASRS) [8] collect reports that are submitted on a voluntary basis. The outputs from this initiative set out to identify system deficiencies and raises correspondence directly with the responsible people. The intention is to affect learning and improvements that correlate with corrective actions that avert event recurrence.

On a wider scale through the diligent offices of the International Civil Aviation Organization (ICAO), standards and recommended practices that define contracting state reporting and analysis obligations, have been developed as a result of the collective efforts of participating states. For example, Annex 13 Aircraft Accident Investigation [9] to the Chicago Convention [10] defines the standards that require states to report accidents involving aircraft with a maximum take-off weight (MTOW) of $2250 \mathrm{~kg}$ and above. The document also contains details of reportable incidents (MTOW $5700 \mathrm{~kg}$ ) that are considered important in terms of safety and accident prevention. An accident/incident data reporting system (ADREP) is operated and managed by ICAO. Safety data from (ICAO) member states are received, verified and retained in the ADREP system. The repository contains an aggregate of occurrences/incidents/accidents reported by the contracting states. The Accident/Incident Reporting Manual [11] document defines the report content, its composition and means of transmittal to ICAO. A common group of general codes known as a taxonomy is used to standardise the inputs for reporting. In an effort to improve harmonisation and exchange of information, most European aviation competent authorities have already migrated to the ICAO common ADREP taxonomy.

The EU, in recognition of its duty of care to the travelling public acknowledges that it must continue to improve levels of aviation safety. Based on a global expectation [12] of the imminent increase in aviation activity, significant challenges are evident if $\mathrm{EU}$ is to only preserve current levels of safety. Presently, air passengers enjoy the benefits of a safe industry based on the technological advancements, recognition of human performance and limitations, compliance primarily with prescriptive regulations and the learning potential arising from past accidents and incidents. The EU regulation 376/2014 [6] was developed to enable the collection, analysis, and follow-up of reportable incidents and occurrences. It mandates provisions for reporters to submit mandatory occurrence reports (MOR's) and voluntary occurrence reports (VOR's). There are discriminating conditions that must be met in order to determine which 'conduit' is required to report a hazard or incident. The regulation also defines reporting timelines for initial reporting (within $72 \mathrm{~h}$ of discovery) and for reporting to the competent authority (within a further $72 \mathrm{~h}$ ). Organisations are also required to have a process in place to implement timely follow-up and notification of their analysis to their competent authority.

In Europe, reporting entities are encouraged to submit reports through a reporting portal moderated by the European aviation safety agency (EASA). Civil aviation competent authorities have access to the portal and the incidents and accidents are categorised in accordance with a standard aviation data reporting program (ADREP) taxonomy. They are then uploaded to a European coordination for accident and incident reporting systems database (ECCAIRS). This multi-modal European transport database can facilitate the collection, analysis and sharing of transport safety data. 


\subsection{Learning from Incidents: Underpinning Theory}

According to Leveson [13], a holistic view of an organisation's capability in terms of learning from incidents can be enhanced by shifting the focus from the individual to what is happening across the system. In the world of 'operational aviation' the concept of Safety Management Systems (SMS) has been for the most part successfully embraced and applied where mandated. Deming [14] the respected purveyor of quality assurance methodologies asks the question, 'what is a system?' He continues to answer, 'a system is a network of interdependent components that work together to try to accomplish the aim of the system'. This description of the system suggests that the process (in safety management parlance) is 'a network of interdependent components'. Safety management philosophy requires specific points to be formally addressed so that the safety management process of operational risk can be explicitly expressed and therefore effectively managed. One of these points is preventing the recurrence of incidents and occurrences through learning from past events to achieve an acceptable level of safety.

Today, in many jurisdictions it is a requirement for aircraft maintenance and continuing airworthiness management organisations to maintain an occurrence-reporting system. European regulatory requirements [6] and organisation procedures [4] normally require the event to be investigated, documented and the causal factors considered. Additionally, corrective and/or immediate actions are often necessary to prevent re-occurrence. Learning from these incidents can often provide potential solutions to preventing safety crises in the future by looking back at what has happened and deriving lessons learned and predicting probable future challenges, [15].

'Learning from incidents' (LFI) is a valuable tool in many domains. Much research has been devoted to understanding how this process can be expressed and measured, how worthwhile lessons can be learned through more efficient and effective learning, as proffered by Drupsteen and Guldenmund [16], Hovden et al. [17] Jacobsson et al. [18]. A main tenet of this reporting system is the ability to report any error or potential error in a 'free and frank' way. This philosophy is intended to be supported by what is termed a just culture, where the outcome for the individual is not based on punitive measures or being inappropriately punished for reporting or co-operating with occurrence investigations. The occurrence reporting system is also intended to be a 'closed-loop' system where feedback is given to the originator and effective actions are implemented within the organisation to address the embryonic or evident safety hazards. The concept is progressive in terms of its potential for contribution to identifying and addressing less than optimal performance of human, organisational and technical systems. Understanding that adverse and unwelcome events can be minimised through diligent reporting, event analysis and learning and subsequent necessary intervention is a positive trait with respect to improving acceptable levels of safety.

Argyris and Schön [19] (pp. 20-21) highlight the importance of learning to detect and address effective responses to errors. Their 'theory in action' concept is the focal point for this determination. The first of its two components, 'theory in use' is one that guides a person's behaviour. This is often only expressed in tacit form and is how people behave routinely. Very often these observed habits are unknown to the individual. The second element is known as 'espoused theory', namely what people say or think they do. Drupsteen and Guldenmund [16] mention that espoused theory comprises of 'the words we use to convey what we do, or what we like others to think we do'.

Enabling this learning channel, ICAO Doc 9859 [19] defines a template for aviation operators and regulators to support the application of a variety of proactive, predictive and reactive oversight methodologies. In addition to routine monitoring schemes, voluntary and mandatory reporting, post incident follow-up; there are regular safety oversight audits. These audits and inspections often set out to establish if there is a difference between espoused theory and the theory in use, e.g., is the task being correctly performed in accordance with the documented procedure/work instruction or is there a deviation from approved data and practice? However, Drupsteen and Guldenmund [16] caution 
auditors not to 'focus too much on the documentation of procedures' alone. In such cases the audit oversight may be ineffective because of its sole focus on espoused theories of the organisation only and not the theory-in-use. They progress to translate this idea of poor focus on theory in action and recommend a solution by suggesting a valid learning component arising from the incidents. They also highlight the 'espoused' aspect where those attempting to learn from incidents often fail to experience the desired learning because outcomes are not fully aligned with the practical objectives of an LFI initiative. For learning to be most effective, espoused theory and theory in use should be reasonably well aligned.

Aircraft maintenance and continuing airworthiness management activities that are performed in European member states are moderated by rules that mandate reporting of defined incidents and occurrences. Repositories of reported data tend to be populated only from sources predominantly aligned with mandatory incident/occurrence reporting requirements. Conventional safety oversight models only verify the presence of reporting media and repositories in this segment of the industry. Traditionally there has been a focus amongst organisations to ensure details of reports are submitted in line with state's mandatory reporting obligations. However, it is possible such a narrow focus on a single element (i.e., reporting alone) of an incident in its lifecycle could negate the potential learning benefits that might accrue from considering other likely related sources. As a result, the absence of clear regulatory requirements capable of augmenting learning from incidents could be considered an impediment to effective learning in the domains affected by EU regulation 1321/2014 [4]. The featured industry sector is regulated by the application and upkeep of numerous requirements in each jurisdictions of operation. In general, oversight duties tend to be carried by regulating states and operators in support of safe and profitable activity. However, a growing tendency to just increase some regulatory requirements across the segments may not always offer the same safety returns necessary for states in the future.

Up until some years ago, basic risk mitigation methods had remained unchanged. The previously reactive initiatives had largely been based on post-event analysis of accidents and incidents. At present, learning from past incidents, occurrences and accidents must be credited with playing a major part in helping evolve the paradigm to the more proactive means of risk management in many aviation segments we know today. Accident models (Heinrich and Reason) can sometimes inadvertently contribute to an over-simplification of how accident and incident contributing factors are perceived. This can result in striving to establish a singular root cause. Understandably the propensity for those tasked with accident and incident investigation is sometimes to establish a linear view based only on apparent causal factors. Proactively identifying precursors to events or potential conditions can greatly assist in averting latent or undiscovered conditions. Since the early 1990s, the potential for organisations to learn from incident precursors and conditions has been worthy of attention. Cooke [20] endorses a suggestion that increased reporting of incidents enhances continuous improvements in high reliability industries. In the continuing airworthiness segment of the industry, here is often a regulatory driven focus on establishing a single root cause. The importance of adequate resources and efforts to determine accurate incident causation and the measures to prevent reoccurrence should be a primary concern. Until ED 2020/002/R [21] is fully implemented, it is possible that the custodians of current regulatory requirements are satisfied once a root cause is established. Could it be that the current popular practice of pursuing (singular) root cause focus can be a lost opportunity when additional related sources exist?

The harvesting of information from incident reporting systems is a necessary input to continuously develop appropriate and effective recurrent training material. The inclusion of basic qualification criteria for human factor trainers in the regulatory requirements should also be addressed. However, it is questionable if the perpetuation of these measures alone would support more effective delivery and application of lessons learned throughout the segment. One means of addressing this impending issue is to remodel regulatory, oper- 
ational and training requirements to consider a new approach in the segment. Reflecting a combination of actions, events and conditions in a new basic model supporting human factor continuation training, may lay the foundations to better elucidate event causation and yield improved and sustainable safety recommendations in the featured segment.

\section{A Model Supporting Learning from Incidents}

\subsection{Model Design and Description}

Currently European measured levels of aviation safety are generally considered as acceptable. As domain activity is expected to increase in the coming decades, further steps to improve or at least preserve contemporaneous levels of safety will have to continue to be developed. One of the main facets of safety management is the reporting, collection, analysis and follow-up to incidents according to Annex 19 [22]. This is also highlighted in an EU communication COM/2011/0670 [23] and (EU) 376/2014 [6]. A primary reason for the emphasis on reporting and subsequent learning from incidents (LFI) is to enable and support a shift from prescribed safety oversight to a risk-based programme. This is seen as the best fit to enable and effect improvements in areas that will present the most risk [24]. Figure 1 presents one view of a generic incident lifecycle [25] integrated with an interactive framework arising from the researchers work. This 'proposed enhancement' could augment a learning dimension in the cycle of an incident.

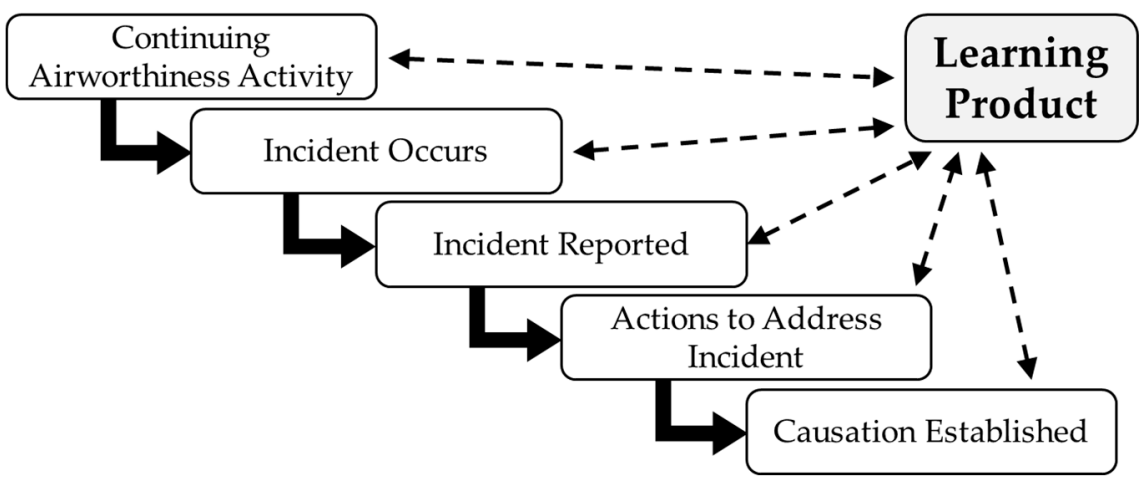

Figure 1. Incident learning product and process (Broken line denotes iterative learning feedback).

Figure 1 also illustrates a view of the overall process employed to acquire, process and store incident data. The 'broken line' arrows signify an iterative action at each stage of processing the incident. The purpose of this is to ask and record what can be learned at each point? The motif of how a learning product originates from the regulatory perspective is also featured. The effectiveness of the learning from the event is considered in terms of how it can be gauged. This is evident from feedback originating from the actions in the cycle when the learning product is being developed. Closing the learning loop is also necessary and reflected in graphic form. In addition to this, assessing actions at each incident stage is intended to support an analysis of how effective resulting actions are in terms of preventing recurrence of the incident. Actions to prevent the recurrence of the same or similar events can be embodied as a result of how effective the learning was. As such the novelty of this framework exists in its clear visual representation rather than the actual arrangement of the specific stages recorded. Traditionally the industry focus on incidents and occurrences has pivoted solely around the reporting requirements. These obligations are the backdrop against which mandatory reporting activity takes place. The establishment of causation is required by regulatory process but little or no suitability of same is mandated by requirement in support of any potential for learning. The featured framework serves to present the main elements of an incident during its lifecycle and highlight the aspects to be considered when incidents are being used in support of developing effective safety lesson delivery. 


\subsection{Model Implementation}

The area of focus for this paper is aircraft maintenance and continuing airworthiness management [4] activities. It was decided to establish contact with an Irish Aviation Authority (IAA) European central repository for aviation accident and incident reports (ECCAIRS) focal point. Following a briefing, a specific permission was granted to review a data set of deidentified mandatory occurrence reports (MOR's) for the purpose of academic analysis. The operational theatre of activity involved licensed air carriers operating large aircraft on the Irish civil aircraft register. The permission allowed an initial physical database search to be performed from June 2019 to November 2019 using 'Part 145 (maintenance) and Part $\mathrm{M}$ (continuing airworthiness management)' as the search terms for de-identified report content. Approximately 200 results came back. The narrative and content of each report was reviewed by the researchers for applicability to the analysis. This exercise refined the reports under review to a data set of 85 . Figure 2 presents an overview of the analysis framework, described in the sequel.

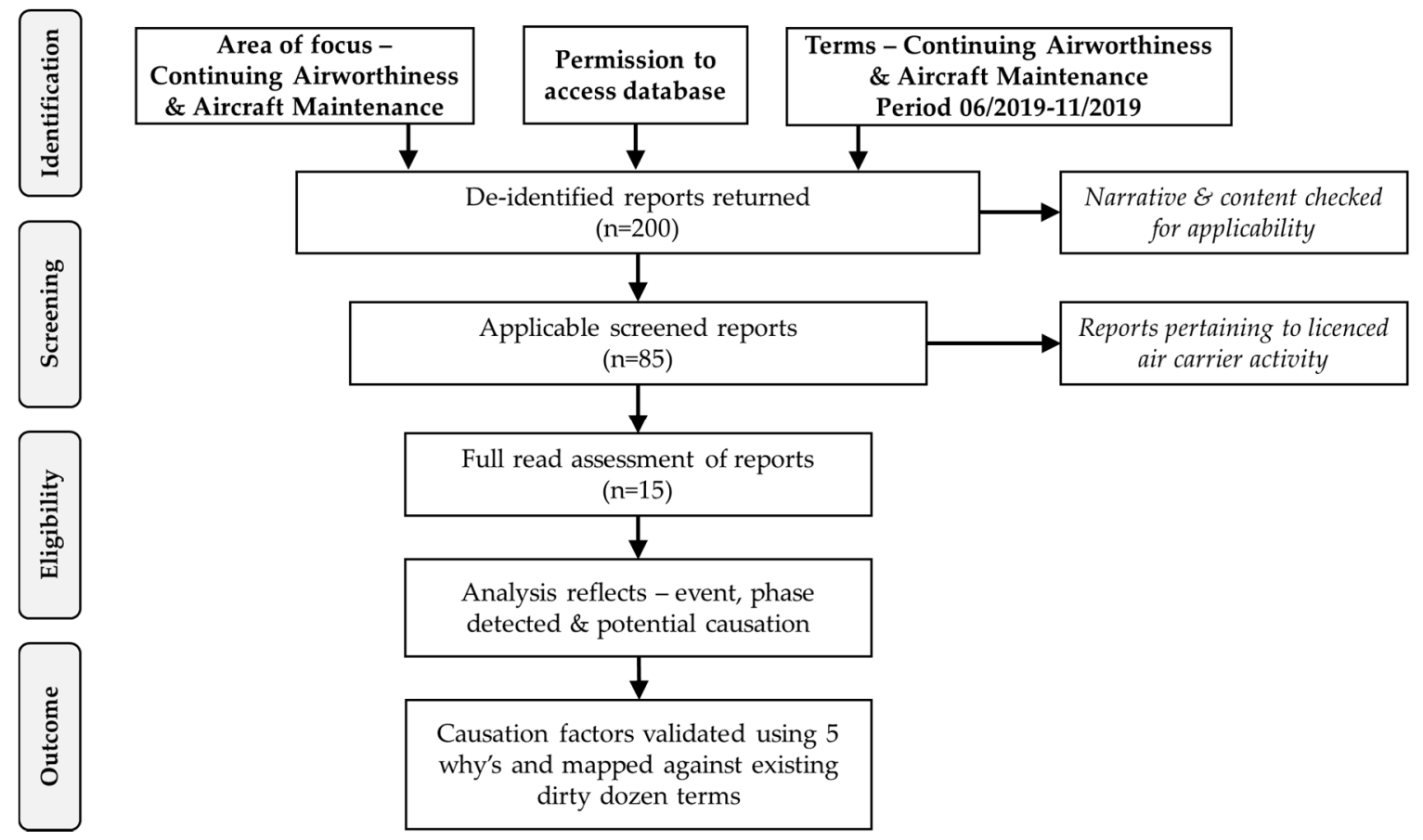

Figure 2. Overview of the analysis framework applied. The systematic review phases (identification-screening-eligibilityoutcome) follow the methodology of Liberati et al. [26].

\subsection{Model Validation: Report Causal Elements}

A third round of full read screening of the set yielded 15 deidentified reports applicable to the exercise topic. Each featured event was considered under the following elements: the actual event, maintenance phase detected and likely potential causation factors. Table 1 contains an overview of this analysis output. Each of the 15 analysed occurrence reports provided a description of the featured event and some were helpfully contextualised with a chronological timeline when included in the report body. This later assisted with appreciating all the potential causation elements for each event. However, the reported verbiage tended to terminate mostly with a focus on consequential impact rather than causal information. For the sake of consistency across the analysis, the authors decided to apply a systematic approach to elicit and validate causal factors from the data. The process was based on a clear definition of root cause as proffered by Paradies and Busch [27] as: 'the most basic cause that can be reasonably identified and the management has control to fix'. 
Table 1. Results of the analysis of 15 incidents and mapping against the 'Dirty Dozen'.

\begin{tabular}{|c|c|c|c|}
\hline & \multirow{2}{*}{ Potential Causation Factors for Each Incident } & \multicolumn{2}{|c|}{ Dirty Dozen 'Taxonomy' } \\
\hline & & Primary & Secondary \\
\hline 1 & $\begin{array}{l}\text { Incorrect tooling } \\
\text { Competence for task } \\
\text { Task sequencing }\end{array}$ & $\begin{array}{c}\text { Lack of resources } \\
\text { Lack of knowledge } \\
\text { (Knowledge, skills, ability) } \\
\text { Complacency } \\
\text { Lack of awareness }\end{array}$ & $\begin{array}{l}\text { Norms established } \\
\text { Lack of communication } \\
\text { Lack of assertiveness }\end{array}$ \\
\hline 2 & $\begin{array}{c}\text { Continuing Airworthiness Management } \\
\text { Organisation (CAMO) management } \\
\text { system competence } \\
\text { Production pressure }\end{array}$ & $\begin{array}{l}\text { Lack of knowledge (procedures } \\
\text { \& knowledge, skills, ability) } \\
\text { Lack of communication } \\
\text { Pressure }\end{array}$ & $\begin{array}{c}\text { Lack of resources } \\
\text { Stress } \\
\text { Fatigue/Stress/Distraction }\end{array}$ \\
\hline 3 & $\begin{array}{l}\text { Inadequate aircraft maintenance programme (AMP) } \\
\text { inspection task } \\
\text { Product design }\end{array}$ & $\begin{array}{l}\text { Norms established } \\
\text { Lack of communication }\end{array}$ & $\begin{array}{l}\text { Lack of awareness } \\
\text { Lack of resources }\end{array}$ \\
\hline 4 & $\begin{array}{c}\text { Inadvertent damage } \\
\text { Incorrect gauge of locking wire \& locking technique }\end{array}$ & $\begin{array}{c}\text { Distraction } \\
\text { Lack of knowledge } \\
\text { (Knowledge, skills, ability) } \\
\text { Fatigue } \\
\text { Lack of teamwork }\end{array}$ & $\begin{array}{l}\text { Complacency } \\
\text { Lack of awareness }\end{array}$ \\
\hline 5 & $\begin{array}{l}\text { CAMO work request incorrect } \\
\text { Maintenance procedure not followed }\end{array}$ & $\begin{array}{c}\text { Lack of knowledge } \\
\text { (Knowledge, skills, ability) } \\
\text { Pressure } \\
\text { Lack of assertiveness }\end{array}$ & $\begin{array}{l}\text { Norms established } \\
\text { Lack of resources }\end{array}$ \\
\hline 6 & $\begin{array}{c}\text { Procedure design } \\
\text { Production pressure } \\
\text { Competence for task } \\
\text { CAMO management system competence }\end{array}$ & $\begin{array}{c}\text { Lack of knowledge } \\
\text { Pressure } \\
\text { Lack of awareness } \\
\text { Lack of communication }\end{array}$ & $\begin{array}{l}\text { Lack of resources } \\
\text { Fatigue/Stress/Distraction } \\
\text { Lack of supervision }\end{array}$ \\
\hline 7 & $\begin{array}{l}\text { Production pressure } \\
\text { Competence for maintenance task }\end{array}$ & $\begin{array}{c}\text { Pressure } \\
\text { Lack of knowledge } \\
\text { (Knowledge, skills, ability) }\end{array}$ & $\begin{array}{l}\text { Fatigue/Stress/Distraction } \\
\text { Lack of resources }\end{array}$ \\
\hline 8 & $\begin{array}{l}\text { Maintenance data availability } \\
\text { Production pressure } \\
\text { Competence for task }\end{array}$ & $\begin{array}{l}\text { Lack of resources } \\
\text { Lack of knowledge } \\
\text { Pressure }\end{array}$ & $\begin{array}{l}\text { Norms established } \\
\text { Fatigue } \\
\text { Lack of awareness }\end{array}$ \\
\hline 9 & $\begin{array}{c}\text { Procedure design } \\
\text { Production pressure } \\
\text { Supervision } \\
\text { Competence for maintenance task }\end{array}$ & $\begin{array}{c}\text { Lack of knowledge } \\
\text { (Procedures) } \\
\text { Pressure } \\
\text { Lack of knowledge } \\
\text { (Knowledge, skills, ability) }\end{array}$ & $\begin{array}{l}\text { Lack of awareness } \\
\text { Lack of communication } \\
\text { Complacency } \\
\text { Lack of assertiveness }\end{array}$ \\
\hline 10 & $\begin{array}{c}\text { Incorrect tooling } \\
\text { Competence for maintenance task } \\
\text { Task sequencing }\end{array}$ & $\begin{array}{c}\text { Lack of knowledge } \\
\text { Lack of awareness } \\
\text { Lack of communication }\end{array}$ & $\begin{array}{l}\text { Norms } \\
\text { Lack of resources }\end{array}$ \\
\hline 11 & $\begin{array}{c}\text { Maintenance data } \\
\text { Procedure design } \\
\text { Production pressure } \\
\text { Competence for maintenance task } \\
\text { Post task leak-check }\end{array}$ & $\begin{array}{c}\text { Lack of knowledge } \\
\text { (Knowledge, skills, ability) } \\
\text { Pressure } \\
\text { Lack of awareness }\end{array}$ & $\begin{array}{c}\text { Lack of teamwork } \\
\text { Complacency } \\
\text { Fatigue/Stress/Distraction } \\
\text { Lack of resources }\end{array}$ \\
\hline 12 & $\begin{array}{c}\text { Production pressure } \\
\text { Competence for maintenance task } \\
\text { Maintenance data availability } \\
\text { Supervision }\end{array}$ & $\begin{array}{c}\text { Pressure } \\
\text { Lack of knowledge } \\
\text { Lack of teamwork }\end{array}$ & $\begin{array}{l}\text { Fatigue/Stress/Distraction } \\
\text { Lack of resources }\end{array}$ \\
\hline
\end{tabular}


Table 1. Cont.

\begin{tabular}{|c|c|c|c|}
\hline & \multirow{2}{*}{ Potential Causation Factors for Each Incident } & \multicolumn{2}{|c|}{ Dirty Dozen 'Taxonomy' } \\
\hline & & Primary & Secondary \\
\hline 13 & $\begin{array}{l}\text { Competence for maintenance task } \\
\text { Production pressure }\end{array}$ & $\begin{array}{l}\text { Lack of knowledge } \\
\text { Pressure }\end{array}$ & Fatigue/Stress/Distraction \\
\hline 14 & $\begin{array}{l}\text { Culture } \\
\text { Risk taking } \\
\text { Competence } \\
\text { Supervision }\end{array}$ & $\begin{array}{c}\text { Norms established } \\
\text { Lack of resources } \\
\text { Lack of knowledge } \\
\text { (Knowledge, skills, ability) }\end{array}$ & $\begin{array}{c}\text { Lack of awareness } \\
\text { Complacency } \\
\text { Lack of communication }\end{array}$ \\
\hline 15 & $\begin{array}{c}\text { CAMO procedure competence } \\
\text { Culture } \\
\text { Supervision }\end{array}$ & $\begin{array}{c}\text { Lack of knowledge } \\
\text { (Knowledge, skills, ability) } \\
\text { Norms } \\
\text { Stress }\end{array}$ & $\begin{array}{l}\text { Lack of awareness } \\
\text { Lack of resources } \\
\text { Pressure }\end{array}$ \\
\hline
\end{tabular}

Many analysis tools [e.g., Fault tree analysis (FTA), functional resonance analysis model (FRAM), systems theoretic accident model and process (STAMP), sequentially timed events plotting (STEP)] are available and can be applied in support of a systematic review aimed at establishing causal factors. However, each of the aforementioned is generally applied in support of more voluminous operational applications and a degree of familiarity and adequate resources are usually required to ensure an efficacious outcome. As the incident reports $(n=15)$ under review already had causal factors ascribed, the authors deemed a simple analysis tool to be appropriate. According to Card [28], the ' 5 Why's technique' is a widely used technique applied in support of root cause analysis and is used by many statutory organisations globally. Ohno [29] (p. 123) highlights that by repeating why five times, the nature of the problem as well as its solution becomes clear. As the authors of this paper were aware, sole reliance on a tool like the 5 Whys has limitations. In particular, exclusive operational reliance on its prowess as a revealing panacea could inveigle its users in to over-simplifying an event and thereby be seduced into pursuing an inappropriate singular cause. As a result, the tool was applied solely as a mechanism to validate the already operator ascribed event categorisations and causal factors.

\section{Results}

Each mandatory occurrence report (MOR) was thoroughly reviewed, and the content of the event and related actions carefully assessed. However, without an intimate knowledge of the operational environment, history of the aircraft reliability and related operational dynamic and contextual influences for example, it was not possible to definitively establish if the recorded causation and related factors were indisputably accurate for each event. Notwithstanding the foregoing, based on the authors experience and judgement the recorded causation factors were harmonised with a taxonomy derived from the elements of the Transport Canada [7] 'dirty dozen' terms associated with common error preconditions. The elements are generally identified as, Lack of communication, Distraction, Lack of resources, Stress, Complacency, Lack of teamwork, Pressure, Lack of awareness, Lack of knowledge, Fatigue, Lack of assertiveness, Norms.

The purpose of aligning the 'potential incident causation factors' with a known taxonomy is to assist with developing clear learning product content and learning objectives. Regulatory code or guidelines for the continuing airworthiness domain do not require a formal approach to learning such as those defined by Bloom [30] and Anderson and Sosniak [31]. Although the reports featured display similar activity profiles, recognition for the need to consider learning taxonomies and the importance of domains of learning (cognitive, affective and psychomotor) when designing continuation training programmes is considered essential. In addition, organisations are not required to have a formal mechanism of assessing efficacy, instead many take comfort in national, European and international holistic safety reports as a means of gauging their performance as part of the collective. 
Assuming the purpose of learning objectives is to assist with the delivery and measurement of the effectiveness of learning actions, developing an overview of a harmonised taxonomy is helpful in this regard.

In Table 1 above, potential causation factors for each of the 15 selected incidents were matched with the twelve elements of the 'Dirty Dozen' human factor taxonomy. In order to prevent an over-simplification of each event's contributing factors, the authors were careful not to be seduced into seeking a singular root cause. Therefore, it was decided to include both primary and secondary human factor elements so that causation could be considered in a holistic manner. The following paragraphs $(\mathrm{a}-\mathrm{h})$ and Figure 3 give a breakdown of the issues emerging from the assessment of the mandatory occurrence reports (MOR's) as seen through the lens of association with a taxonomy.

a. Lack of knowledge features as a primary element in $13(87 \%)$ of 15 occurrences. This can be closely related to the competence required to perform the task as it relates to aircraft maintenance and continuing airworthiness management activities which are defined as comprising of 'knowledge, skills and attitude/ability' [4]. As a secondary potential contributing element, it relates to only $1(7 \%)$ of the 15 occurrences.

b. Lack of awareness is highlighted as a primary potential causation factor in $9(60 \%)$ of the 15 reviewed occurrences. This element can be closely related to competence, communication and teamwork. As a secondary contributing factor, lack of awareness was noted during the review in 5 (33\%) of 15 reviewed occurrences.

c. Lack of resources were recorded in $3(20 \%)$ of 15 events. Adequate resources are required in order for an operator to adequately staff an organisation so that an aircraft can be maintained to the correct standard and when required. EU 1321/2014 [4] mandates that a manpower plan is maintained in support of ensuring adequate levels of staff are consistently available. As a secondary issue, lack of resources appeared as an issue in 5 (33\%) of 15 cases. Ultimately, accountable managers are the key to ensuring sufficient resources are made available so that the organisational elements continue to remain compliant and effective in this respect.

d. Norms accounted for $3(20 \%)$ of 15 reports examined. Norms are often viewed as behaviours that are developed and accepted within a group. However, when the resulting behaviour requires a deviation from approved procedural function, the consequences are often unknown. Although such actions may offer short-term productivity gains, they may also introduce active and latent safety hazards. In the case of secondary causation, norms are associated with 8 (53\%) of 15 assessed occurrences.

e. Lack of communication was found to be evident in $3(20 \%)$ of 15 occurrences in the study. Communication in aircraft maintenance and management activities is a vital element in the release of a safe product. Poor communication can amplify many other elements of the human factors leading to a deterioration in human performance, Chatzi [32], Chatzi et al. [33]. 2 (13\%) of the 15 reviewed communication-related occurrences were recorded as contributing to secondary event causation.

f. Complacency was revealed as a primary factor in the causation of $1(7 \%)$ of 15 events studied. However, as a secondary contributing factor it accounted for 5 (33\%) of 15 reports. Stress levels associated with a task can diminish performance if one becomes complacent. Its presence can contribute in concert with other elements capable of setting the scene for an unwelcome event.

g. Stress as a primary factor appeared in $1(7 \%)$ of the 15 reviewed events. However, it was associated with $2(13 \%)$ of 15 reports as a secondary issue. Stress can be both a by-product and an enabler of other Dirty Dozen elements. Fatigue for example can be closely coupled to stress and displayed similar pattern in the study with $7 \%$ and $13 \%$ respectively of prevalence in the reports reviewed.

h. Lack of assertiveness was evident as a primary and as a secondary causation factor in both cases and occurring at rate of $1(7 \%)$ of 15 events under review. Distraction and lack of teamwork appeared in similar proportions in the review results. 


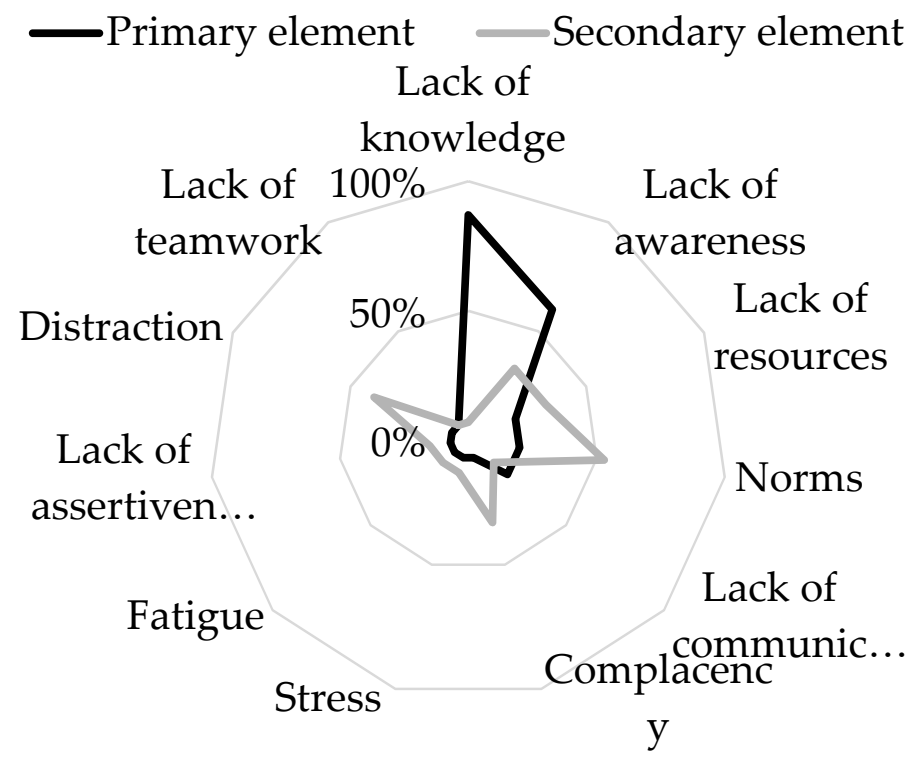

Figure 3. Representation of primary and secondary causation in the reviewed occurrence reports.

\section{Discussion}

Recalling the causal factors attributed to the featured occurrence reports in the paragraphs above, it is easy to appreciate their relationships with the 'Dirty Dozen' example of human factor elements. For example, lack of resources can be a major constraint when it comes to providing adequate levels of appropriately qualified competent staff. Pressures exerted upon staff in a dynamic industry sector to absorb additional workload can of course have a potentially detrimental effect on safe operations. Competent and available supervision of maintenance and inspection staff is a core requirement of a quality mission in aircraft maintenance and continuing airworthiness management operations. In many regions the maintenance requirements (e.g., EU regulation 1321/2014 [4]) stipulate a process whereby all staff must meet the qualification criteria and be deemed competent before unaccompanied work can take place. For the purpose of the discussion, key elements of the incident cycle components are examined through pertinent elements identified during the analysis. The iterative approach suggested during the management of the incident information is supported by the context outlined below. Understanding the relevance of each of the sections is intended to support more effective learning outcomes. The following paragraphs discuss the incident cycle from the perspective of developing a sound learning product.

\subsection{Acquiring, Processing and Storing Incident Data}

According to Garvin [34], a clear definition of learning has proven to be elusive over the years. Garvin suggests 'a learning organization is an organization skilled at creating, acquiring and transferring knowledge and at modifying its behaviour to reflect new knowledge and insights'. Figure 1 illustrates the evolution of an incident as it is managed through its cycle. The incident/occurrence will need to be detected if it is to possess any potential for learning. Acquiring information in support of learning is one of the key actions. Such learning material originates from compliance audits, amended regulatory requirements, best practice, and incidents and occurrence reports. Within the greater area of aircraft maintenance and continuing airworthiness management, details of incidents and occurrences tend to be reported soon after an event. Reporting requirements are normally timebound (i.e., $72 \mathrm{~h}$ ). Most organisations endeavour to notify the necessary stakeholders as soon as possible, often by telephone in the first instance. As many airline staff are employed on a shift work basis, the window of $72 \mathrm{~h}$ is useful in support of administering the reporting function. It is not unusual to have numerous points of contact for reporting within organisations. However, reporting generally follows a consistent route regardless of who the initial point 
of contact is. Some organisations appear to empower and encourage the submission of reports by any individual. Other organisations appear to endorse reporting through a 'chain of command'. Regardless of the chosen initial reporting route input, all reports are progressed to a 'gate-keeper' within an organisation. The people responsible initially for examining the validity and completeness of submitted reports often hold a key position in either the quality assurance, technical services or maintenance departments. Generally, there is a strong awareness of the need to report incidents and occurrences classified as mandatory. There may be numerous motivational reasons to report, such as ethical, safety, compliance with regulatory requirements and best practice for example. Those submitting reports embrace mandatory reporting as an obligation underpinned by the cultural norms of aircraft maintenance and continuing airworthiness management. When an issue is discovered, it is progressed through the reporting system regardless of its status. Many organisations welcome all reports including non-mandatory events that are highlighted through voluntary reporting streams. They evidently see value in including them in their analysis of events and the subsequent learning opportunities the reports may offer.

\subsection{Single, Double and Triple-Loop Learning}

From an organisational point of view, single-loop learning can be experienced when an error is detected and corrected but little else changes, Argyris and Schön [19] (p. 18). In aircraft line maintenance environments where a 'find and fix' ethos prevails, singleloop learning is often evident. It is not unusual for technical issues to befall an aircraft's departure time. Such pressure points often associated with fulfilling contractual obligations may have a negative impact on the potential for learning from a related event. In such cases, if issue arises the matter may be resolved without any further recorded action. Because of the terse nature of the experience for an individual concerned, the opportunity for further learning may not extended beyond the single loop. Argyris and Schön [19] (p. 21) and Lukic et al. [35] proffer double-loop learning as learning that takes place and results in organisational norms and theory in use being altered. Presently, aircraft certifying, and support staff are obliged to continuously preserve an adequate understanding of the aircraft being maintained and managed along with associated regulations and procedures. A desired outcome of double-loop learning is often witnessed for example through the adjustment of environmental, behavioural and procedural norms. Instances of double-loop learning can be evident following unsuccessful attempts through singleloop learning. In-service continuation training is an effective enabler that is capable of supporting double-loop learning. Organisations are also required by EU 1321/2014 [4] to establish and maintain a continuation training programme for staff. A primary pillar of continuation training syllabi is the use of incidents and occurrences as lesson content for influencing organisational norms and behaviour in support of preventing recurrence of incidents and occurrences. Deutero-learning (triple-loop) relates to when members of an organisation reflect upon previous learning and sets about to improve how the organisation can refine and improve the process of learning from events, Argyris and Schön [19] (p. 29), Bateson [36]. This could also be stated as learning how to learn by seeking to improve single and double loop learning. Although deutero-learning may be considered as a natural extension of other levels of learning, the concept does not feature as a requirement in aircraft maintenance and continuing airworthiness management regulatory codes.

\subsection{Learning Product}

Aircraft maintenance and management regulatory codes require reporting of 'any identified condition of the aircraft or component that has resulted or may result in an unsafe condition that hazards seriously the flight safety' [4]. Generally, a learning product can originate from numerous information sources within the aircraft maintenance and continuing airworthiness management arena. Specifically, GM1 145.A.30(e) [4] requires the use of accident and incident reports in support of the mandatory human factors training content. The intent of this material is to ensure information is imparted upon 
the organisations' staff in support of preventing the subject event reoccurrence. Such continuation training is mandated by European requirements for all aircraft maintenance and continuing airworthiness management organisations. Continuation training is also a product as well as a medium for imparting learning from incidents. Inputs to continuation training syllabi often feature learning from incidents and experience augmented by safety notices, toolbox talks and are recognised as a means of presenting the learning product to operational staff. Drupsteen and Guldenmund [16] cite, 'Lampel et al. [37] where they use the term "learning about events"'. This is further explained as 'information about events is shared and diffused to help create new ideas', in this case in the support of safe operations.

\subsection{Effectiveness of Learning}

The evaluation of any initiative's success is much more straight forward when clear objective indicators (learning outcomes) are employed. In the case of learning in an aircraft maintenance and management environment, organisations can generally employ indicators such as inspection non-compliance, audit findings and rates of incident reoccurrence in support of gauging the effectiveness of learning. Probing salient aspects such as timely investigation of incidents, assessing the learning content and feedback are a starting point for assessing effectiveness. Cooke [20] concludes the absence of or poor information can compromise the effectiveness of feedback. He also suggests that if the feedback cycle is ailing, the climate may deteriorate and have a negative impact upon organisational safety. From a commercial viewpoint, it is perhaps understandable that aircraft tend to only generate revenue when flying. However, airline operators need to maintain a balance between safe operations and productivity. It is essential that incident causal factors are fully identified and adequate time and resources are available to support this important aspect of learning. Cooke [20] endorses a suggestion that increased reporting of incidents enhances continuous improvement in high reliability industries. However, establishing adequate causation is also an attribute capable of supporting effective learning from an event in dynamic environments.

The importance also of just culture as an enabler for incident reporting and subsequent effective learning cannot be ignored. Under-reporting of events resulting from a single-loop learning experiences amongst operational maintenance staff and production pressures can also impact negatively upon efforts to propagate a learning environment. McDonald [38] suggests from their analysis, 'that there is a strong professional sub-culture, which is relatively independent of the organization. One implication of this finding is that this professional subculture mediates the effect of the organizational safety system on normal operational practice'. Von Thaden and Gibbons [39], conclude safety culture 'refers to the extent to which individuals and groups will commit to personal responsibility for safety; act to preserve, enhance and communicate safety information; strive to actively learn, adapt and modify (both individual and organizational) behaviour based on lessons learned from mistakes .........'. A just culture is defined in the affecting regulation EU 376/2014 [6] as, 'a culture in which front line operators or other persons are not punished for actions, omissions, or decisions taken by them, that are commensurate with their experience and training, but in which gross negligence, wilful violations and destructive acts are not tolerated'. Accordingly, a just culture is a fair culture. The effectiveness of the learning system can also be compromised by its efficiency as well as its inadequacies. The volume of information that staff must process and assimilate is continually increasing. Guardians of learning outcomes should be mindful that staff risk becoming information weary as a result of the ever-increasing demands on their cognitive abilities.

\subsection{Types of Knowledge}

This relates to; conceptual, dispositional, procedural and locative knowledge forms [40]. One of the key objectives of learning from incidents is to identify the type of knowledge needed to prevent an issue recurring. When a reportable issue for example is discovered, the submitted report will identify 'what' happened. Subsequent follow-up will set out to determine 'why' the issue occurred. The guiding principles of 'how' to perform the 
task or operation are often contained in procedures or data particular to the task. The information contained in procedures will enable a person to utilise other forms of knowledge. Prevailing culture within an organisation will have an impact on learning from incidents. If a strong commercial culture exists, this may have an impact on for example the depth and breadth of learning from incidents within the company. Induction and initial training for new staff is an important element for demonstrating where organisational sources of information can be accessed. Accident data repositories contain many well documented examples of human factor related precursors to incidents. Many of which may have originated in poor access to approved data and culminated in serious and possibly preventable incidents. Acknowledging and addressing the limitations related to the types of knowledge when developing continuation training programmes would have a positive impact on participants. The enabling industry requirements do not specify any discernible differences in how the types of knowledge are differentiated. A review of the human factors syllabus requirements did not highlight a need to appreciate or account for these human centred limitations when designing and delivering training lessons.

\section{Conclusions}

It has been highlighted during this research that the opportunity to learn from incidents is not being fully embraced in the aircraft maintenance and continuing airworthiness management segment of the industry. While the idea of eliminating all incidents is a fallacy, reducing their numbers and potential for harm is a reality. Air travel is on the increase and it is envisaged that current sectors flown will have doubled within the next two decades. If current levels of safety were to remain stagnant with a doubling in activity, twice the current fatality rate would surely not be acceptable. Many people relate safety to freedom from risk and danger [41]. Unfortunately, risk and danger are often ubiquitous in the presence of aircraft maintenance and continuing airworthiness management activities. Managing sources of risk and danger is a tall order for some organisations. Document 9859 [42] recognises that 'aviation systems cannot be completely free of hazards and associated risks'. However, the guidance does acknowledge that as long as the appropriate measures are in place to control these risks, a satisfactory balance between 'production and protection' can be achieved. Perrow [43] (p. 356) acknowledges that 'we load our complex systems with safety devices in the form of buffers, redundancies, circuit breakers, alarms, bells, and whistles' because no system is perfect.

Detecting and identifying hazards highlighted through incident reporting systems is recommended by ICAO standards and recommended practices as an effective means of achieving practicable levels of safe operations. Therefore, objective data mined from a reporting system offers the potential to enlighten aviation stakeholders and to illuminate weakness that may be present. Such information can assist with a better understanding of events and augment mitigating measures against the potential effects of these hazards. When incidents occur, this can be an indication of a failure in an organisation's process and/or practice. Because of continuous challenges faced by organisations in the aviation industry, there is still potential to learn from resulting incidents and pre-cursors. The learning is based on the potential new knowledge available from the associated collection, analysis and interventions for these events. Effective learning can be considered as a successful translation of safety information into knowledge that actively improves the operating environment and helps prevent recurrence of unwelcome events.

The paper features a brief exercise to demonstrate how safety information can be translated into lessons capable of augmenting knowledge within an aircraft maintenance and management organisation. To support this, fifteen occurrences drawn from an ECCAIRS incident database portal were analysed. The result of the analysis along with potential causation factors are presented. Additionally, a simple mechanism in support of the delivery of associated safety lessons was developed and is presented in Table 1 above. Integrating the known causal factors with the 'Dirty Dozen' taxonomy which is already associated with this aviation segment provides a useful template for continuation 
training in the segment. The emerging incident/occurrence themes related to the featured events are briefly discussed and presented within the document. The publication also introduces a framework that assembles and explains the main elements of an incident within its lifecycle. The purpose of this is to illustrate tacit aspects of an incident that have the potential to augment learning within the process. In order to leverage the maximum benefit from details of an incident, learning processes must recognise the existence of these event components. There can therefore be a formal approach to gauging the effectiveness of learning and a means of identifying underperforming elements of the learning process.

This publication could assist subject organisations with a review of their management of incident information when developing continuation training material and learning outcomes.

Author Contributions: Conceptualization, J.C. and K.I.K.; methodology, J.C.; formal analysis, J.C.; investigation, J.C.; validation, J.C and K.I.K.; data curation, J.C.; writing - original draft preparation, J.C. and K.I.K.; writing-review and editing, J.C. and K.I.K. All authors have read and agreed to the published version of the manuscript.

Funding: This research received no external funding.

Institutional Review Board Statement: Not applicable.

Informed Consent Statement: Informed consent was obtained from all subjects involved in the study.

Data Availability Statement: The data presented in this study are available on request from the corresponding author.

Conflicts of Interest: The authors declare no conflict of interest.

\section{References}

1. Silva, S.A.; Carvalho, H.; Oliveira, M.J.; Fialho, T.; Guedes Soares, C.; Jacinto, C. Organizational practices for learning with work accidents throughout their information cycle. Saf. Sci. 2017, 99, 102-114. [CrossRef]

2. Akselsson, R.; Jacobsson, A.; Bötjesson, M.; Ek, Å.; Enander, A. Efficient and effective learning for safety from incidents. Work 2012, 41, 3216-3222. [CrossRef] [PubMed]

3. Document 32018R1139. Regulation (EU) 2018/1139 of the European Parliment and the Council of 4 July 2018 on common rules in trhe field of civil aviation and establishing a European Union Aviation Safety Agency, and amending Regulations (EC) No 2111/2005, (EC) No 1008/2008, (EU) No 996/2010, EU376/2014 and Directives 2014/30/EU of the European Parliment and the Council, and repealing Regulation (EC) No 216/2008 of the European Parliment and of the Council and Council Regulation (EEC) No 3922/91. In Official Journal of the European Union; European Commission: Brussels, Belgium, 2018; pp. 1-122.

4. Document 32014R1321. Commission Regulation (EU) No 1321/2014 of 26 November 2014 on the continuing airworthiness of aircraft and aeronautical products, parts and appliances, and on the approval of organisations and personnel involved in these tasks. In Official Journal of the European Union; European Commission: Brussels, Belgium, 2014; pp. 1-194.

5. Harvey, C.; Stanton, N.A. Safety in System-of-Systems: Ten key challenges. Saf. Sci. 2014, 70, 358-366. [CrossRef]

6. Document 32014R0376. Regulation (EU) No 376/2014 of the European Parliament and of the Council of 3 April 2014 on the reporting, analysis and follow-up of occurrences in civil aviation, amending Regulation (EU) No 996/2010 of the European Parliament and of the Council and repealing Directive 2003/42/EC of the European Parliament and of the Council and Commission Regulations (EC) No 1321/2007 and (EC) No 1330/2007. In Official Journal of the European Union; European Commission: Brussels, Belgium, 2014; pp. 18-43.

7. Transport Canada. Human Performance Factors for Elementary Work and Servicing; Canada, T., Ed.; Transport Canada: Ottawa, ON, Canada, 2003.

8. FAA. 120-92B-Safety Management Systems for Aviation Service Providers; Federal Aviation Administration: Washington, WA, USA, 2015.

9. ICAO. ICAO Annex 13 to the Convention on International Civil Aviation: Aircraft Accident and Incident Investigation. In Issue 10 Amendment 14; ICAO: Montreal, QC, Canada, 2010.

10. ICAO. Convention on International Civil Aviation; Doc 7300; ICAO: Montreal, QC, Canada, 1944.

11. ICAO. ICAO Accident/Incident Reporting Manual, 3rd ed.; ICAO: Montreal, QC, Canada, 2014.

12. Boeing. Current Market Outlook 2015-2034; Boeing: Chicago, IL, USA, 2015.

13. Leveson, N. A new accident model for engineering safer systems. Saf. Sci. 2004, 42, 237-270. [CrossRef]

14. Deming, W. The New Econonics for Industry, Government, Education, 2nd ed.; MIT Press: Cambridge, MA, USA, 2000.

15. Bond, J. A Janus Approach to Safety. Process. Saf. Environ. Prot. 2002, 80, 9-15. [CrossRef]

16. Drupsteen, L.; Guldenmund, F.W. What is Learning? A Review of the Safety Literature to Define Learning from Incidents, Accidents and Disasters. J. Contingencies Crisis Manag. 2014, 22, 81-96. [CrossRef] 
17. Hovden, J.; Størseth, F.; Tinmannsvik, R.K. Multilevel learning from accidents-Case studies in transport. Saf. Sci. $2011,49,98-105$. [CrossRef]

18. Jacobsson, A.; Ek, Å; Akselsson, R. Method for evaluating learning from incidents using the idea of "level of learning". J. Loss Prev. Process Ind. 2011, 24, 333-343. [CrossRef]

19. Argyris, C.; Schön, D.A. Organizational Learning II: Theory, Method, and Practice; Addison-Wesley Publishing Company: Boston, MA, USA, 1996.

20. Cooke, D.L. A system dynamics analysis of the Westray mine disaster. Syst. Dyn. Rev. 2003, 19, 139-166. [CrossRef]

21. ED Decision 2020/002/R. Amending the Acceptable Means of Compliance and Guidance Material to Annex I (Part-M), Annex II (Part-145), Annex III (Part-66), Annex IV (Part-147) and Annex Va (Part-T) to as well as to the articles of Commission Regulation (EU) No 1321/2014, and issuing Acceptable Means of Compliance and Guidance Material to Annex Vb (Part-ML), Annex Vc (Part-CAMO) and Annex Vd (Part-CAO) to that Regulation. In Official Journal of the European Union; European Commission: Brussels, Belgium, 2020.

22. ICAO. Annex 19 to the Convention on International Civil Aviation Safety Management. In Safety Management; ICAO: Montreal, QC, Canada, 2013.

23. Document 52011DC0670. Communication from the Commission to the Council and the European Parliament Setting up an Aviation Safety Management System for Europe. In Setting up an Aviation Safety Management System for Europe; European Commission: Brussels, Belgium, 2011.

24. Cooke, D.L.; Rohleder, T.R. Learning from incidents: From normal accidents to high reliability. Syst. Dyn. Rev. 2006, 22, 213-239. [CrossRef]

25. Drupsteen, L.; Groeneweg, J.; Zwetsloot, G.I. Critical steps in learning from incidents: Using learning potential in the process from reporting an incident to accident prevention. Int. J. Occup. Saf. Ergon. 2013, 19, 63-77. [CrossRef] [PubMed]

26. Liberati, A.; Altman, D.G.; Tetzlaff, J.; Mulrow, C.; Gøtzsche, P.C.; Ioannidis, J.P.A.; Clarke, M.; Devereaux, P.J.; Kleijnen, J.; Moher, D. The PRISMA statement for reporting systematic reviews and meta-analyses of studies that evaluate healthcare interventions: Explanation and elaboration. BMJ 2009, 339, b2700. [CrossRef] [PubMed]

27. Paradies, M.; Busch, D. Root cause analysis at Savannah River plant (nuclear power station). In Proceedings of the Conference Record for 1988 IEEE Fourth Conference on Human Factors and Power Plants, Monterey, CA, USA, 5-9 June 1988; pp. 479-483.

28. Card, A.J. The problem with '5 whys'. BMJ Qual. Saf. 2017, 26, 671-677. [CrossRef] [PubMed]

29. Ohno, T. Toyota Production System: Beyond Large-Scale Production; CRC Press: Boca Raton, FL, USA, 1988.

30. Bloom, B.S. Taxonomy of Educational Objectives; Cognitive Domain; Edwards Bros: Ann Arbor, MI, USA, 1956; Volume 20, p. 24.

31. Anderson, L.W.; Sosniak, L.A. Bloom's Taxonomy; Chicago Press: Chicago, IL, USA, 1994.

32. Chatzi, A.V. The Diagnosis of Communication and Trust in Aviation Maintenance (DiCTAM) Model. Aerospace 2019, 6, 120. [CrossRef]

33. Chatzi, A.V.; Martin, W.; Bates, P.; Murray, P. The unexplored link between communication and trust in aviation maintenance practice. Aerospace 2019, 6, 66. [CrossRef]

34. Garvin, D.A. Building a Learning Organization; Harvard Business Review July-August: Brighton, MA, USA, 1993 ; Volume 71.

35. Lukic, D.; Littlejohn, A.; Margaryan, A. A framework for learning from incidents in the workplace. Saf. Sci. 2012, 50, 950-957. [CrossRef]

36. Bateson, G. The Logical Categories of Learning and Communication. Steps to an Ecolology of Mind; Ballantine Books: New York, NY, USA, 1972; pp. 279-308.

37. Lampel, J.; Shamsie, J.; Shapira, Z. Experiencing the improbable: Rare events and organizational learning. Organ. Sci. 2009, 20, 835-845. [CrossRef]

38. McDonald, N.; Corrigan, S.; Daly, C.; Cromie, S. Safety management systems and safety culture in aircraft maintenance organisations. Saf. Sci. 2000, 34, 151-176. [CrossRef]

39. Von Thaden, T.L.; Gibbons, A.M. The Safety Culture Indicator Scale Measurement System (SCISMS); National Technical Information Service Final Report; Office of Aviation Research and Development: Washington, DC, USA, 2008; pp. 1-57.

40. Thorndike, E.L. Fundamental theorems in judging men. J. Appl. Psychol. 1918, 2, 67. [CrossRef]

41. Reason, J.T. Managing the Risk of Organisational Accidents; Ashgate Publishing: Farnham, UK, 1997.

42. ICAO. Safety Management Manual; Doc 9859; ICAO: Montreal, QC, Canada, 2013.

43. Perrow, C. Normal Accidents Living with High-Risk Technologies. In With a New Afterword and a Postscript on the Y2K Problem; Perrow, C., Ed.; Princeton University Press: Princeton, NJ, USA, 1999. 